\title{
REAL LIFE ANTICOAGULANT TREATMENT FOR STROKE PREVENTION IN PATIENTS WITH NONVALVULAR ATRIAL FIBRILLATION
}

\author{
MONICA SABĂU ${ }^{1,2}$, OTILIA ȚICA ${ }^{1,2 *}$, FILIP CHEȚAN ${ }^{3}$, OVIDIU ȚICA ${ }^{1}$, ALEXANDRA \\ COMĂNESCU ${ }^{1,2}$, LIANA ANTAL ${ }^{1}$, MARIANA MUREȘAN ${ }^{1,2}$, VIORELA ENĂCHESCU ${ }^{4}$, \\ CAMELIA DIACONU ${ }^{5}$, CRISTINA BIDIAN ${ }^{6}$
}

${ }^{1}$ Faculty of Medicine and Pharmacy, University of Oradea, Oradea, Romania

${ }^{2}$ Emergency County Clinical Hospital of Oradea, Oradea, Romania

${ }^{3}$ Emergency Universitary Hospital, Bucharest, Romania

${ }^{4}$ University of Medicine and Pharmacy of Craiova, Craiova, Romania

${ }^{5}$ University of Medicine and Pharmacy "Carol Davila", Bucharest, Romania

" "Iuliu Hațieganu” University of Medicine and Pharmacy Cluj-Napoca, Romania

*corresponding author: otilia_cristea01@yahoo.com

\begin{abstract}
Atrial fibrillation (AF) represents the most frequent cause of cardioembolic stroke. The aim of the study was to evaluate the patterns of anticoagulant treatment in patients admitted for stroke due to non-valvular atrial fibrillation (NVAF). The main inclusion criteria in the study was the diagnosis of cardioembolic stroke in patients admitted to our hospital between November 2016 and February 2017. We evaluated different subtypes of AF related to stroke. A number of 108 patients with NVAF were included. Of the 90 patients known with NVAF, 41 had received recommendation for anticoagulant therapy, but only 27 followed the treatment. An important percentage of patients with stroke, treated with vitamin K antagonists (VKA), were not optimally anticoagulated, being at risk both for thromboembolic risk and haemorrhagic events. An important percentage of patients with stroke, treated with VKA, are not optimally controlled (INR outside the therapeutic range), exposing them at risk for thromboembolic and also haemorrhagic events. In real life settings, in Romania, only a small number of patients with NVAF receive NOAC treatment.
\end{abstract}

\section{Rezumat}

Fibrilația atrială (FA) reprezintă cea mai frecventă cauză de accident vascular cerebral cardioembolic. Scopul studiului a fost de a evalua tratamentul anticoagulant la pacienții internați cu diagnosticul de accident vascular cerebral din cauza fibrilației atriale non-valvulare (FANV). Criteriul principal de includere în studiu a fost diagnosticul de accident vascular cerebral cardioembolic al pacienților internați în spitalul nostru între noiembrie 2016 și februarie 2017. Am corelat diferitele subti puri de FA cu accidentul vascular cerebral. Un număr de 108 pacienți cu FANV au fost identificați. Dintre cei 90 de pacienți cunoscuți cu FANV, 41 au avut recomandare de tratament anticoagulant, dar numai 27 au urmat tratamentul. Un procent important de pacienți cu AVC, trataţi cu AVK, nu au fost anticoagulați optim, prezentând risc înalt atât tromboembolic cât şi hemoragic. Un procent important din pacienții cu stroke, tratați cu AVK, nu sunt controlați optim (INR în afara intervalului terapeutic), expunându-i la risc atât pentru evenimente tromboembolice cât și hemoragice. În practica zilnică, în Romania, numai un număr redus de pacienți cu FANV primesc tratament cu noile anticoagulante orale.

Keywords: stroke, atrial fibrillation, cardioembolism

\section{Introduction}

Stroke represents the second-leading cause of mortality and a leading cause of long-term disability. Despite the reduction of stroke incidence, stroke of cardioembolic causes has tripled during the last decades and it is estimated that it will triple again by 2050 [24]. Atrial fibrillation (AF) is incriminated to be responsible of a 3 to 5 fold increase of stroke risk [23]. An ascending trend of AF prevalence is observed $[9,14,21]$. AF represents the most frequent cause for cardioembolic stroke. Approximately $15 \%$ of all strokes, and up to one-third of ischemic strokes involve octogenarian patients with AF [13].

Anticoagulant therapy represents the cornerstone standard of care for stroke prevention in AF patients [15]. Vitamin K antagonists (VKA) have proven their efficiency in cardioembolic stroke prevention. However, VKA, although largely used, are currently associated with many drug and food interactions and are incriminated in high readmission rates [5].

Through modifying pathways of the clotting cascade or by targeting thrombin directly, anticoagulant agents inhibit thrombogenesis [1]. VKA block the conversion 
FARMACIA, 2020, Vol. 68, 5

of vitamin $\mathrm{K}$ into the active complex (a vitamin epoxide). This implies the gamacarboxilation of the coagulation factors II, VII, IX and X at the hepatic level $[4,15]$. VKA is rapidly absorbed in the intestine and is metabolised by the cytochrome P450 in the liver. The anticoagulant effect appears within 2 days, but the complete effect occurs only after 5 - 6 days of treatment, because it largely depends on the prothrombin level decrease (prothrombin has an increased halflife compared to coagulation factors VII and X). Therefore, it is necessary to associate VKA with heparin until obtaining an efficient therapeutic level $[3,8]$.

Limitations of VKA, such as interactions with numerous foods and drugs, as well as the need for frequent coagulation monitoring and dose adjustments, have resulted in their underuse [5]. Even when prescribed, the level of anticoagulation with VKA is frequently outside the therapeutic range, compromising safety and efficacy. The international normalised ratio (INR) is a standardized laboratory test used to assess the anticoagulant efficacy of VKA. However, in current clinical practice, the INR level control is frequently inappropriate. A "well controlled" patient on VKA is the one whose INR barely fluctuates, but it is not frequently encountered in daily practice. The time in therapeutic range (TTR) reflects the quality of anticoagulation and represents the estimated total percentage of time that the INR is within the target range (2.0 3.0). Usually, the Rosendaal method is preferred for calculating the TTR. When achieving a TTR over $70 \%$, the patient is considered optimally controlled [22]. The VKA shortcomings urged the development of non-vitamin $\mathrm{K}$ oral anticoagulants (NOAC). Their advantages, like a fixed dose with no need for routine laboratory monitoring, a lower bleeding risk, no food interactions, fewer drug interactions, make them a compelling alternative to VKA. Disadvantages, like cost, are taken into account by physicians when prescribing NOAC, but a shared decision with the patient should be made when choosing the anticoagulant. Analyses integrating the laboratory monitoring costs and the costs of strokes or major bleeding indicate that NOAC are cost-effective for stroke prevention $[15,22]$.

Dabigatran, rivaroxaban, and apixaban are new oral anticoagulants, non-vitamin $\mathrm{K}$, that have important advantages over VKA. Dabigatran etexilate is a prodrug. Only after oral ingestion, the compound is hydrolysed (by non-specific plasma and hepatic esterases) into the active anticoagulant, dabigatran. Dabigatran binds reversible, competitive to thrombin (at the activation site) $[13,15]$.

NOAC proved to be non-inferior to VKA for stroke prevention in patients with NVAF [10]. Most are small synthetic molecules that target thrombin (dabigatran etexilate) or factor Xa (rivaroxaban, apixaban, edoxaban, betrixaban). NOAC are available anticoagulant agents used as alternatives to "classical" ones. Due to their rapid onset of action and their half-life, their posology allows once or twice daily administration. The direct oral anticoagulants are small molecules; they bind reversible to the targeted enzyme at the active site. Clinical trials comparing dabigatran, rivaroxaban, or apixaban with warfarin for stroke prevention in $\mathrm{AF}$ revealed important differences in the safety profiles of these agents [18]. Several validated stroke risk $\left(\mathrm{CHA}_{2} \mathrm{DS}_{2}-\mathrm{VASC}\right)$ or haemorrhagic risk (HAS-BLED) assessment tools are available for use in patients with $\mathrm{AF}$ [15].

The aim of the study was to evaluate and appreciate the patterns of anticoagulant treatment in patients admitted for cardioembolic stroke due to NVAF in the Emergency County Clinical Hospital of Oradea, Romania.

\section{Materials and Methods}

\section{Study population}

A retrospective, observational, descriptive, longitudinal study was conducted among adult patients who have been discharged from the Emergency County Clinical Hospital of Oradea, Romania, with the diagnosis of stroke. The study was based on a quantitative research, using the existing electronic database of our hospital system, between November 2016 and February 2017. We evaluated a total of 420 patients consecutively discharged from the Neurology Department.

The main inclusion criteria in the study was the diagnosis of cardioembolic stroke. Since all the patients enrolled in the study had AF and stroke, they achieved at least 2 points in the $\mathrm{CHA}_{2} \mathrm{DS}_{2}$-VASc score (clinical prediction score for estimating the risk of stroke in patients with atrial fibrillation). Following the current European Society of Cardiology guidelines, all patients had an indication for anticoagulant treatment. Patients who met the inclusion criteria, but died within the specified observation interval, were also included in the study. Patients with other types of stroke, not related to NVAF, were excluded.

The anticoagulant treatment prescription and administration in the neurology department was analysed based on the cardioembolic stroke types. The patients were divided in two groups: the first group included patients who were using VKA (acenocoumarol) and the second group included patients under treatment with NOAC. Evaluation, data acquisition

The data were obtained from the patients' medical records; the clinical relevant information, as well as the treatment (at admission, during hospitalization and at discharge), were recorded. AF and stroke were diagnosed and classified as defined by the European Society of Neurology, European Society of Cardiology and the European Heart Rhythm Association. Ischemic or haemorrhagic stroke was certified by cerebral computed tomography (performed during hospitalization 
or in the emergency department) and neurological evaluations. The current research has been conducted in accordance with the ethical principles set out by the Helsinki Declaration and Good Clinical Practice Recommendations and was approved by the hospital's Ethics Committee.

Statistical methodology

All statistical analyses were performed using a statistical analysis software. Results are presented as mean \pm standard deviation (SD) (for numeric variables) or percentages. Continuous normal distribution variables were reported as mean and SD. The categorical variables were reported as percentages. Continuous variables were analysed for normalization and compared using the Student $t$ test; they were expressed by mean and standard and/ or median deviation. The correlation degrees (r) between the studied parameters were evaluated by calculating the Pearson correlation

coefficient. A p $<0.05$ limit value was considered statistically significant. Intergroup comparisons were performed using either the Chi-square test to evaluate to what extent the differences between the independent and dependent variables are statistically significant. Later, we tested the assumptions (controlling the independent variables) using the simple logistic regression method, to identify the direct effects and potential mistaken effects.

\section{Results and Discussion}

During the period of study, we evaluated 420 patients hospitalized with stroke. A number of 342 (80.7\%) patients had ischemic stroke and $78(19.3 \%)$ had haemorrhagic stroke. We found NVAF in 108 (26.2\%) patients. We considered as the group of study the one that included patients with stroke and NVAF.

Table I

AF and cardioembolic stroke in our study

\begin{tabular}{|l|c|c|c|}
\hline \multicolumn{1}{|c|}{ Variables assessed } & Ischemic stroke & Haemorrhagic stroke & p value \\
\hline AF first diagnosed & 16 & 2 & 0.081 \\
\hline Paroxysmal AF & 4 & 0 & 0.047 \\
\hline Persistent AF & 36 & 3 & 0.038 \\
\hline Long-standing persistent AF & 17 & 3 & 0.031 \\
\hline Permanent AF & 24 & 3 & 0.025 \\
\hline
\end{tabular}

During the study, one of the patients had a readmission, 28 days after the first discharge. A significant percentage $(83.4 \%)$ of patients were known to have paroxysmal/persistent/permanent AF before the vascular event for which they were hospitalized and only a small percentage (16.6\%) were diagnosed with new AF during the current admission. The description of patients with stroke and subtypes of AF can be seen in Table I.

Almost two-thirds $(68.3 \%)$ of the patients had their first stroke, while one third had at least one other ischemic stroke in their history. No patient had a history of haemorrhagic stroke. The percentage of recurrent stroke could be explained in part by the high risk of these patients and the fact that secondary prophylaxis is not effective.

The $\mathrm{CHAD}_{2} \mathrm{DS}_{2}$ VASC and HAS-BLED scores calculated for these patients are shown in Figures 1 and 2 .

All patients had the $\mathrm{CHAD}_{2} \mathrm{DS}_{2} \mathrm{VASc}$ score $\geq 2$, with indication for anticoagulation. The HAS-BLED score was $\geq 3$ in almost a third of the patients.

The mean $\mathrm{CHA}_{2} \mathrm{DS}_{2}-\mathrm{VASC}$ score in our study vas 4.1, with a SD of 1.353. The mean HAS-BLED score in our study was 2.1 , with a SD of 0.832 .

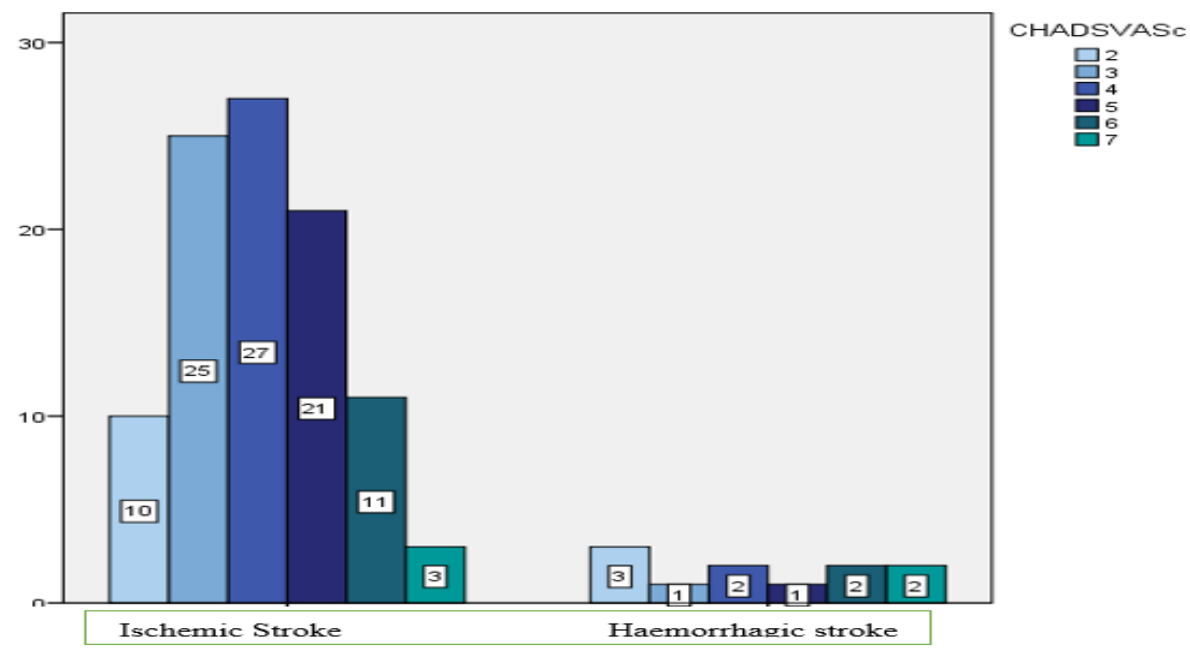

Figure 1.

$\mathrm{CHA}_{2} \mathrm{DS}_{2}$-VASC score among patients 


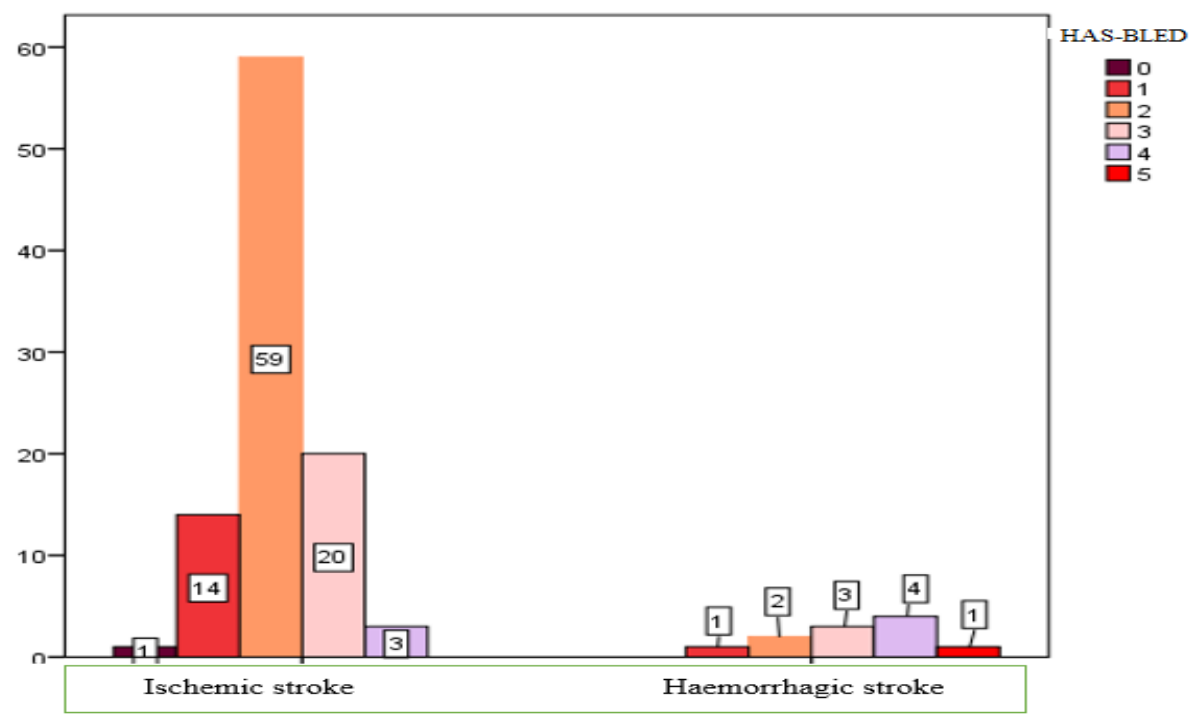

Figure 2.

Registered HAS-BLED score

Of the 81 patients with previously known ischemic stroke, $57.4 \%$ never received recommendation for anticoagulant therapy. All the patients with paroxysmal AF were in this group. A number of 34 patients received recommendation of anticoagulant treatment, but only a quarter followed the treatment, $16.3 \%$ did not follow or discontinue treatment for over a month. Of the 9 known patients with AF who had haemorrhagic stroke, $21.2 \%$ never received recommendation for treatment, and from the $78.8 \%$ with a recommendation, $66.5 \%$ followed the treatment.
By analysing all the patients known with $\mathrm{AF}$ on admission, irrespective of the type of stroke, $54.7 \%$ had no anticoagulant therapy recommended, $45.3 \%$ had an anticoagulant recommended, but only $29.4 \%$ followed the treatment, while $15.2 \%$ did not take or discontinued the treatment. We described in Figure 3 the patients' adherence to anticoagulant treatment.

Of the 36 patients who had a history of stroke, $60.8 \%$ had no recommendation for anticoagulation and $39.2 \%$ of patients had anticoagulation recommendation; a percentage of $28.7 \%$ patients followed the treatment, and $10.5 \%$ of the patients had no changes in their treatment.

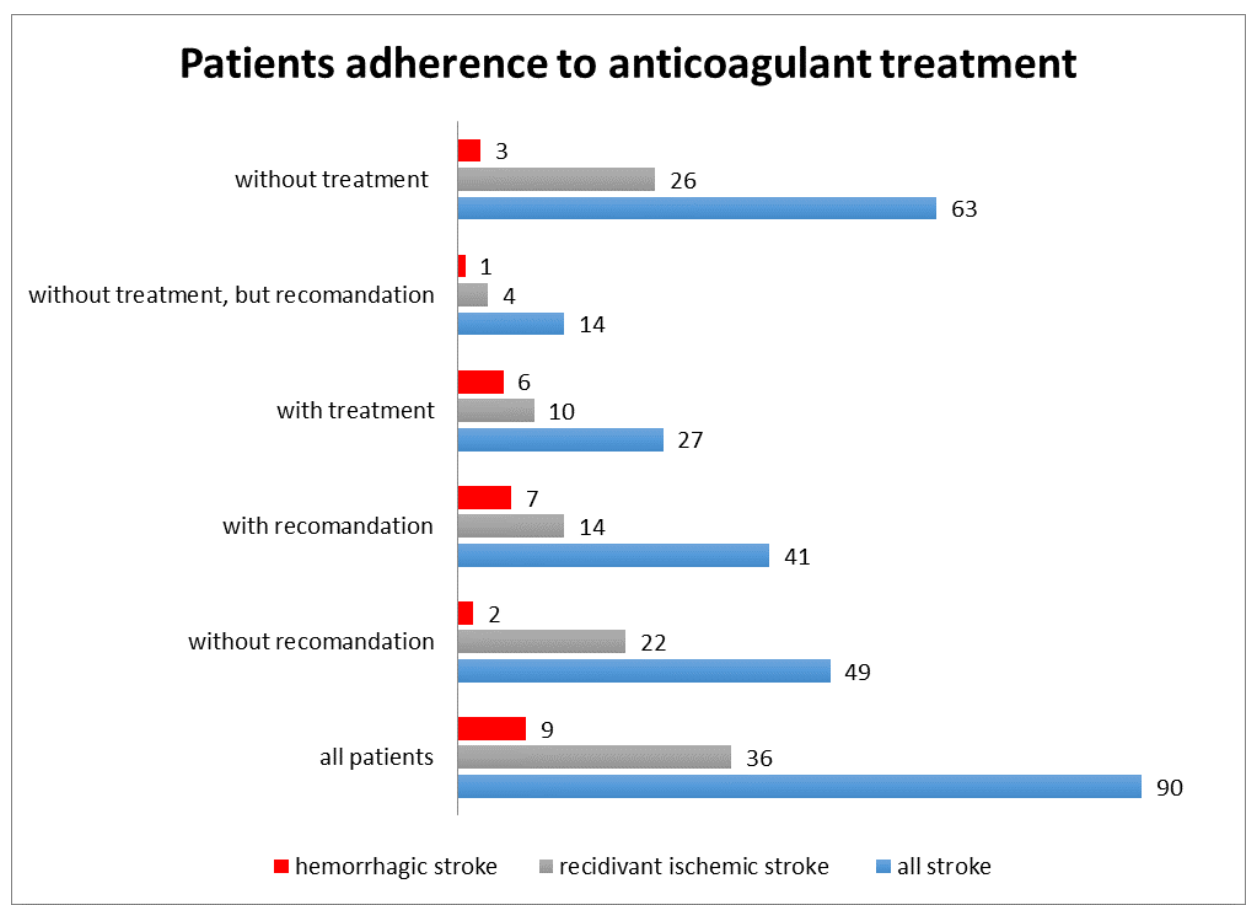

Figure 3.

Patients' adherence to anticoagulant treatment 
FARMACIA, 2020, Vol. 68, 5

Of 27 treated patients, $15.4 \%$ used NOAC and $84.6 \%$ had VKA treatment. The small number of patients taking NOAC is due, most likely, to the fact that these drugs are not reimbursed by the national health insurance system, and patients cannot afford the medication costs.

Of those treated with VKA, more than half (59.8\%) were under the recommended dose, with a INR value $<2$, approximately $(10.6 \%)$ were in the therapeutic range, with a INR of $2-3$, and almost a third had overdosed their VKA, with a value of INR > 3 , outside the therapeutic range. Our study shows, however, an extremely small number of patients in the therapeutic range: only $10.6 \%$.

From the 71 patients with ischemic stroke discharged at home, 62 patients received anticoagulants (NOAC was prescribed in $28 \%$ of the patients), 5 patients received antiplatelet drugs and 4 had no antiplatelet drug recommendation, because they had a haemorrhagic transformation of the stroke. In Figure 4 we present the discharge treatment of our patients.

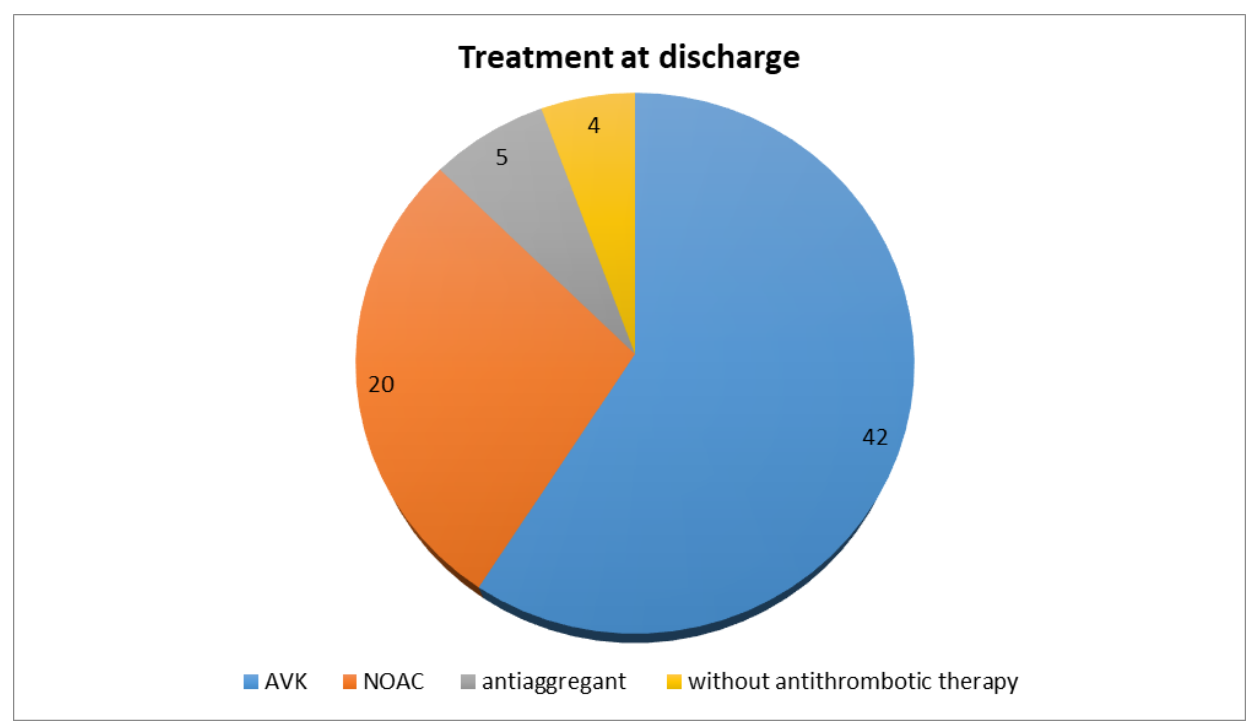

Figure 4.

Discharge treatment in the study

The anticoagulant therapy patterns among stroke patients with NVAF have been approached in large studies $[10,11]$. We aimed to describe anticoagulant medication patterns among a sample of patients with NVAF admitted into our department. This study provides insights into the anticoagulant therapy prescribed and taken upon hospital admission, during hospitalization and discharge prescriptions among NVAF patients. Romanian studies about the in-hospital anticoagulant therapy are limited and, to our knowledge, a descriptive analysis of this type of consumption has not been done. The possibility that a patient with NVAF admitted for stroke receives an anticoagulant is high. Our study' objective was to assess the anticoagulant therapy and patients' adherence in a Romanian county hospital, in order to offer a glimpse of the reality of these drugs prescription.

Mark et al. presented a group of 272 patients with stroke and AF, in whom they retrospectively collected data of the last approx. 1000 days [16]. However, the authors do not mention the number of admissions in this interval or the number of beds for hospitalization. Although a comparison is not possible, we have identified the patients from our study in only 122 days, in a clinic with only 30 beds. This increased incidence can be determined by an inadequate prescribing/monitoring of anticoagulation in patients with NVAF.

It is known that out of 10 patients with NVAF and stroke, one patient has haemorrhagic stroke and 9 patients ischemic strokes.

National and European registries regarding AF [5] and anticoagulants prescription reveal a patient close to one from the real life, outside the rigurosity of a clinical trial, but the in-hospital intake and administration of this drugs are relatively scarce; for this reason, descriptive analysis of this intake is limited.

The data from the current study regarding the risk scores are similar with those found in the literature [5]. As outlined by the European registries [5], we can encounter a high variability across European regions regarding the prescription of NOAC, highlighting the lack of adherence to guidelines' recommendations, which recommend NOAC over VKA $[15,22]$. In an earlier analysis of the European AF registry, patients from the Southeast Europe were less likely to be treated in accordance with the guidelines [2].

A study performed in Romania about self-monitoring of INR in patients treated with VKA showed that this method is appropriate for supporting patients to monitor their VKA activity [19]. 
The therapeutic perspectives in anticoagulant therapy offer new opportunities, enhance the therapeutic horizon and improve the quality of life in these patients. The thrombo-prophylaxis with VKA in patients with NVAF is limited, due to the INR suboptimal control. All patients from our study received proper treatment of their underlying disease and associated comorbidities. A shared decision involving the latest information on the efficiency, safety and protocols regarding the anticoagulant use and prescription need to be done (patients, doctors and pharmacists, general practitioners) $[15,20,22]$.

Also, it is worth to stress out the significant number of patients who, although had a recommendation for anticoagulant treatment, did not follow the treatment. Adherence to treatment is a major problem in patients with long-term medication and the acceptance of haemorrhagic risks is a matter to be considered [25]. Suboptimal guideline adherence and underuse of anticoagulants in patients with atrial fibrillation have been reported worldwide [2, 22]. The bleeding risk assessment scale (HAS-BLED score) should not be understood as a reason to exclude patients with high scores $(\geq 3)$. This score is useful for the attending physician in order to be careful to correct the bleeding risk and to periodically re-evaluate the patient. Patients should be informed, educated to monitor and to treat their risk factors (arterial hypertension, for example), to avoid drugs that interfere with anticoagulant medication (non-steroidal anti-inflammatory drugs), to monitor their treatment and adjust doses in order for the INR to be kept between 2 - 3 and TTR of $70 \%$ (if they are under treatment with VKA) [12]. Although, the current recommendations are known by cardiologists, neurologists and family doctors, medical practice shows a large number of patients who do not receive this treatment or do not follow it correctly [17]. Studies of how therapeutic agents are used in clinical practice may be useful in implementing treatment guidelines [6, 7].

NOAC are challenging the traditional anticoagulant agents in a large population, due to their efficacy, fixed dosing regimens, more stable therapeutic window and decreased risk of bleedings.

The study limitations arise from the fact that this is a single-centre non-randomized study, without a control group. The data shown in this study represent the clinical practice in our centre, so it cannot be generalized. The study was not performed to evaluate the efficacy or safety of NOAC versus VKA in patients with stroke, but to offer some in-hospital patterns of the clinical practice regarding the anticoagulant treatment in Romania.

\section{Conclusions}

An important percentage of patients with stroke, treated with VKA, are not optimally controlled (INR outside the therapeutic range), exposing them at risk for thromboembolic and also haemorrhagic events. In real life settings, in Romania, only a small number of patients with NVAF receive NOAC treatment. There is a significant number of patients who do not follow or discontinue treatment at their own initiative. Medical education is extremely important, but neglected.

\section{Conflict of interest}

The authors declare no conflict of interest.

\section{References}

1. Adams CD, Anger KA, Greenwood BC, Fanikos J, Antithrombotic pharmacotherapy. Chapter 110. In: Irwin and Rippe's intensive care medicine. $7^{\text {th }}$ ed. Philadelphia, PA: Lippincott, Williams, and Wilkins; 2012; 1224-1242.

2. Admassie E, Chalmers L, Bereznicki LR, Changes in oral anticoagulant prescribing for stroke prevention in patients with atrial fibrillation. Am J Cardiol., 2017; 120(7): 1133-1138

3. Ageno W, Gallus AS, Wittkowsky A, Crowther M, Hylek EM, Palareti G, Oral anticoagulant therapy: antithrombotic therapy and prevention of thrombosis, $9^{\text {th }}$ ed: American College of Chest Physicians EvidenceBased Clinical Practice Guidelines. Chest, 2012; 141: e44S-88S.

4. Diaconu C, Bălăceanu A, Bartoş D, The landscape of rehospitalization in chronic heart failure patients: need for an integrated approach. Arch Balk Med Union, 2014; 49(3): 247-250.

5. Diaconu C, Heart failure - keeping step with the progress. Arch Balk Med Union, 2018; 53(2): 1771178.

6. Daina L, Carp Gh, Neamţu C, Venter A, Armeanu P, Antibiotherapy in hospital - between the efficiency and quality of medical services. The role of the drug committee. Farmacia, 2015; 63(3): 407-412.

7. Daina LG, Neamţu C, Daina CM, Evaluating the analgesic consumption in a clinical emergency hospital. Farmacia, 2017; 65(3): 360-367.

8. Dogliotti A, Paolasso E, Giugliano RP, Novel anticoagulants in atrial fibrillation. Clin Cardiol, 2013; 36(2): 61-66.

9. Go AS, Hylek EM, Phillips KA, Chang Y, Henault LE, Selby JV, Singer DE, Prevalence of diagnosed atrial fibrillation in adults: national implications for rhythm management and stroke prevention: the AnTicoagulation and Risk Factors in Atrial Fibrillation (ATRIA) Study. JAMA, 2001; 285: 2370-2375.

10. Halperin JL, Hankey GJ, Wojdyla DM, Piccini JP, Lokhnygina Y, Patel MR, Breithardt G, Singer DE, Becker RC, Hacke W, Paolini JF, Nessel CC, Mahaffey KW, Califf RM, Fox KA, ROCKET AF Steering Committee and Investigators, Efficacy and safety of rivaroxaban compared with warfarin among elderly patients with nonvalvular atrial fibrillation in the Rivaroxaban Once Daily, Oral, Direct Factor Xa Inhibition Compared With Vitamin K Antagonism for Prevention of Stroke and Embolism Trial in Atrial Fibrillation (ROCKET AF). Circulation, 2014; 130(2): 138-146 
11. Halvorsen S, Atar D, Yang H, De Caterina R, Erol C, Garcia D, Granger CB, Hanna M, Held C, Husted S, Hylek EM, Jansky P, Lopes RD, Ruzyllo W, Thomas L, Wallentin L, Efficacy and safety of apixaban compared with warfarin according to age for stroke prevention in atrial fibrillation: observations from the ARISTOTLE trial. Eur Heart J., 2014; 35(28): 1864-1872.

12. Higashi M, Veenstra DL, Wittkowsky AK, Influence of CYP2C9 genetic variants on the risk of over anticoagulation and of bleeding events during warfarin therapy. JAMA, 2002; 287: 1690-1698

13. Huber K, Connolly SJ, Kher A, Christory F, Dan GA, Hatala R, Kiss RG, Meier B, Merkely B, Pieske B, Potpara T, Stępińska J, Klun NV, Vinereanu D, Widimský P, Practical use of dabigatran etexilate for stroke prevention in atrial fibrillation. Int J Clin Pract., 2013; 67(6): 516-526.

14. Kamel H, Healey JS, Cardioembolic Stroke. Circul Res., 2017; 120(3): 514-526.

15. Kirchhof P, Benussi S, Kotecha D, Ahlsson A, Atar D, Casadei B, Castella M, Diener HC, Heidbuchel H, Hendriks J, Hindricks G, Manolis AS, Oldgren J, Popescu BA, Schotten U, Van Putte B, Vardas P, ESC Scientific Document Group; 2016 ESC Guidelines for the management of atrial fibrillation developed in collaboration with EACTS. Eur Heart J., 37(38): 2893-2962,

16. Mark L, Dani G, Vendrey R, Paragh G, Katona A, Oral anticoagulant therapy and bleeding events with vitamin $\mathrm{K}$ antagonists in patients with atrial fibrillation in a Hungarian county hospital. Med Sci Monit., 2015; 17: 518-525.

17. Melamed OC, Horowitz G, Elhayany A, Vinker S, Quality of anticoagulation control among patients with atrial fibrillation. Am J Manag Care, 2011; 17: 232-237
18. Nutescu EA, Oral anticoagulant therapies: Balancing the risks. Am J Health-Syst Pharm., 2013; 70(10 Suppl.1): S3-S11.

19. Pleșa CF, Nicolae C, Sîrbu CA, Nemeș R, Păunescu A, Țânțu MM, Use of anticoagulants in cerebral vascular pathology. Farmacia, 2019; 67(1): 27-33.

20. Popescu R, Bratu O, Spînu D, Marcu D, Farcaș, C, Dinu M, Mischianu D, Neuroendocrine differentiation in prostate cancer - A review. Rom J Milit Med., 2015; 118(3): 16-19.

21. Rahman F, Kwan GF, Benjamin EJ, Global epidemiology of atrial fibrillation. Nature Rev Cardiol., 2014; 11: 639-654.

22. Steffel J, Verhamme P, Potpara TS, Albaladejo P, Antz M, Desteghe L, Haeusler KG, Oldgren J, Reinecke H, Roldan-Schilling V, Rowell N, Sinnaeve P, Collins R, Camm AJ, Heidbüchel H, ESC Scientific Document Group; The 2018 European Heart Rhythm Association Practical Guide on the use of nonvitamin $\mathrm{K}$ antagonist oral anticoagulants in patients with atrial fibrillation: executive summary. EP Europace, 2018; 20(8): 1231-1242.

23. Wolf PA, Abbott RD, Kannel WB, Atrial fibrillation as an independent risk factor for stroke: the Framingham Study. Stroke, 1991; 22: 983-988.

24. Yiin GS, Howard DP, Paul NL, Li L, LuengoFernandez R, Bull LM, Welch SJ, Gutnikov SA, Mehta Z, Rothwell PM; Oxford Vascular Study. Age-specific incidence, outcome, cost, and projected future burden of atrial fibrillation-related embolic vascular events: a population-based study. Circulation, 2014; 130: 1236-1244.

25. Zullig LL, Stechuchak KM, Goldstein KM, Olsen MK, McCant FM, Danus S, Crowley MJ, Oddone EZ, Bosworth HB, Patient-reported medication adherence barriers among patients with cardiovascular risk factors. J Manag Care Spec Pharm., 2015; 21: 479-485. 